Sebastian Dorsch, Verfassungskultur in Michoacán (Mexiko). Ringen um Ordnung und Souveränität im Zeitalter der Atlantischen Revolutionen, Colonia, Weimar, Viena, Böhlau, 2010, 634 p.

\title{
Ulrike Bock*
}

Westfälische Wilhelms-Universität Münster/Alemania

$\mathrm{C}^{\mathrm{l}}$ nuevo enfoque que propone el llamado giro cultural se aprecia cada vez más en el campo de las humanidades, especialmente en las ciencias históricas. Esta novedosa propuesta empieza a tomarse en cuenta en otras disciplinas como la historia constitucional, tradicionalmente marcada por la historia del derecho y las ciencias políticas. Es en este contexto donde recientemente se ha acuñado el concepto de cultura constitucional (en alemán Verfassungskultur), que aboga por comprender las constituciones no sólo como fenómenos jurídicos, sino también como fenómenos culturales. Originalmente este concepto se estableció para diferenciar las constituciones premodernas de las modernas. ${ }^{1}$ Sin embargo, en los últimos años también se le usa para la época moderna. De allí resultan dos diferentes dimensiones para el estudio de las constituciones reglamentadas, es decir, establecidas de manera positiva. Por un lado, se puede desentrañar el proceso de elaboración de una constitución desde una determinada cultura política (y así analizar esta constitución como expresión de las normas y valores de una sociedad); por otro, la constitución misma puede ser interpretada como un elemento caracterizador de la cultura política. Por lo tanto, en el contexto de este enfoque, se pone de relieve la manera cómo se transmite el orden constitucional, p. ej. en el acto de su pro-

*ulrike.bock@uni-muenster.de

Título en español: La cultura constitucional en Michoacán (México). Lucha por el poder y la soberanía en la era de las revoluciones del Mundo Atlántico.

${ }^{1}$ Para una aclaración del uso del concepto "Constitución” también para la época premoderna, que, como es sabido, no conocía ningún documento constitucional que establecía un derecho positivo, véase Silke Hensel, "Introducción: Constitución, poder y representación”, en Silke Hensel, coord., en colaboración con Ulrike Bock y Katrin Dircksen, Constitución, poder y representación. Dimensiones simbólicas del cambio politico en la época de la independencia mexicana, Madrid, Frankfurt, Iberoamericana, 2011 (en prensa). 
mulgación. ${ }^{2}$ Desde esta última perspectiva, se puede examinar la comunicación por parte de los gobernantes, y con ello la escenificación del poder del Estado, así como la recepción de esta comunicación y, por ende, las interpretaciones y apropiaciones que adoptan aquellos que son gobernados.

En el libro aquí reseñado, en el que se publican los resultados de su tesis doctoral, Sebastian Dorsch intenta unir ambas perspectivas: la de la creación de las normas constitucionales y la de los procesos de su transmisión comunicativa. En este contexto, la atención del autor se centra en lo que él denomina "los imaginarios, las expectativas y los modelos de argumentación” (en alemán "die Vorstellungswelten, Erwartungshaltungen und Argumentationsmuster", p. 2) de los actores investigados, en este caso, los diputados del Congreso de Michoacán, encargados primero de la redacción, y luego de las reformas de la constitución estatal. En consecuencia, en su trabajo Dorsch recurre sobre todo a fuentes discursivas y normativas, como las actas de sesión de este congreso o la legislación expedida durante la época estudiada.

Este libro se divide en tres extensas partes. La primera, dedicada a la cultura constitucional en Michoacán desde la época colonial hasta la proclamación de la independencia de México en 1821, resume bien la literatura existente sobre el tema. Aquí, junto a la acentuación de las tendencias regionalistas manifiestas ya durante la era colonial tardía, el autor subraya cuán determinante fue la guerra civil del periodo de 1810-1821 para la cultura política de la región michoacana. Al mismo tiempo, se trasluce cómo las posibilidades de representación inauguradas por la Constitución de Cádiz establecieron nuevos estándares, a pesar de que el orden gaditano en Michoacán sólo se implantará por completo a partir de 1820 .

La segunda parte se centra en el Congreso Constituyente de Michoacán establecido después de la proclamación de la República federal en 1824. En ella, el autor, mediante el estudio de la legitimación y los

${ }^{2}$ Desde luego, en los países de habla española, el concepto "cultura constitucional" parece estar connotando más bien la primera perspectiva mencionada, es decir, la que entiende la elaboración de una constitución como expresión de una cierta cultura política. También se estudia la comunicación de los valores y de las normas constitucionales, pero estas investigaciones normalmente no figuran bajo el término "cultura constitucional". 
objetivos de la constitución michoacana, analiza en concreto las concepciones del orden de los diputados así como el proceso de construcción de los poderes estatales. Entre sus primeras conclusiones, Dorsch destaca especialmente dos aspectos. Por un lado, las múltiples referencias discursivas de los diputados muestran a Michoacán como una región inserta en el mundo atlántico, por lo que Dorsch la define con el concepto de "región atlantizada" (en alemán "atlantisierte Region", p. 283). En concordancia con investigaciones más recientes, el autor presta especial importancia a la influencia de la Constitución de Cádiz, aunque al mismo tiempo subraya las apropiaciones selectivas que hicieron los diputados, basados en sus experiencias cercanas. Con esta posición, el autor contradice las interpretaciones eurocentristas, que consideran las constituciones americanas como simples transferencias deficitarias del modelo europeo. Por otro lado, siguiendo la propuesta de Dieter Grimm, Dorsch caracteriza a la Constitución de Michoacán como una carta fundamental, en sí misma constituyente de poder en contraposición a muchas constituciones europeas de la época, que más bien modificaban el poder existente. ${ }^{3}$ Según Dorsch, las posibilidades emergentes de esta situación llevaron a que en el proceso constituyente, el debate sobre problemas concretos desempeñara un papel más importante que una confrontación ideológica entre los diputados. Ya en esta parte del libro,el autor seńala algunas conclusiones que en el transcurso del texto reiterará. Entre éstas, se destacan el establecimiento del congreso estatal como la principal institución en la región, interpretado como "reemplazo del monarca" ("Ersatz-Monarch", p. 214), y la función de la constitución para crear un sentido de comunidad. Por tanto, y como consecuencia de la destrucción del orden político y social experimentado en el marco de la guerra civil, se le atribuyó gran importancia a la idea de formación de la comunidad, más que a la de formar los ciudadanos como individuos.

Sin embargo, es en la tercera parte donde se halla el verdadero núcleo de este trabajo. Aquí el autor analiza los discursos, las prácticas y

${ }^{3}$ Dieter Grimm, Constitucionalismo y derechos fundamentales, Serie Estructuras y procesos: Derecho, Madrid, Trotta, 2006. En alemán, Grimm emplea respectivamente los términos herrschaftskonstituierend y herrschaftsmodifizierend. 
el establecimiento de las leyes y normas por parte de las legislaturas regulares hasta 1835. Como aspecto central se da prioridad al modo en que las relaciones entre el pueblo (como soberano) y el congreso (como su representante) debían estructurarse. Para ello, Dorsch aborda tres campos: las elecciones, las concepciones sobre la sociedad de los diputados y la puesta en escena del congreso mismo. También en el análisis de estos campos el autor mantiene su interés por las concepciones del orden sociopolítico de los diputados. En este contexto, la percepción de los diputados sobre las elecciones se describe como una "relación de confianza asimétrica" ("asymmetrische Vertrauensbeziehung", p. 325), que se basaba en su desconfianza fundamental frente al pueblo. Por lo tanto, el procedimiento electoral indirecto de tres niveles, introducido ya con la Constitución de Cádiz, debía servir como una especie de filtro restrictivo para guarnecer el orden sociopolítico. Cabe mencionar que en Michoacán, las reformas del derecho electoral se refirieron sobre todo a las juntas electorales del nivel local con el objetivo de reforzar sus reglamentaciones e impedir el establecimiento de facciones políticas.

A esta percepción del pueblo como un elemento poco confiable, los diputados, por un lado, contrapusieron la imagen del ciudadano ideal, mientras que, por otro, atribuyeron el modelo de la familia tradicional al papel del estado de Michoacán como entidad corporativa. En este sentido, al congreso le correspondía el rol de un padre de familia cuidadoso, que al mismo tiempo se le debía sumisión. Asimismo, se debía contrarrestar la amenaza de un posible "deshilachamiento" de la sociedad mediante la escenificación de una comunidad caracterizada por el sentido de responsabilidad y la orientación hacia el bienestar público. $\mathrm{Al}$ representar preferentemente a los "mártires" y no tanto a los "héroes", estas puestas en escena pretendían construir una comunidad unida por sus anteriores sacrificios. En este contexto, Dorsch destaca la falta de referencias a tradiciones constitucionales (como, por ejemplo, la Constitución de Apatzingán) y subraya la relativa escasez de alusiones conmemorativas que hacían referencia a la constitución michoacana, en especial, si se compara con la política de conmemoración de la Constitución de Cádiz. A estos dos factores, el autor atribuye que en Michoacán tempranamente se estableciera una pérdida de confianza en 
el concepto de la nación de ciudadanos, de tal manera que para la cimentación de la idea de comunidad se recurriera más bien a metáforas como la de la "familia natural".

Por último, al estudiar su puesta en escena, el autor retoma su argumento sobre la posición especial del congreso en Michoacán. Dorsch postula la tesis de una despersonalización consciente del poder, cuya escenificación debía guardar al nuevo orden de las críticas del pueblo. Para ello, el autor transfiere el concepto de los "dos cuerpos del rey", ${ }^{4} \mathrm{de}$ Ernst Kantorowicz, al congreso de Michoacán. Así, Dorsch contrasta la puesta en escena de un comportamiento marcado por una actitud crítica aunque colegial, evidente durante las deliberaciones al interior del congreso, con las escenificaciones de cara a su exterior, orientadas esencialmente hacia la ritualización y hacia su diferenciación consciente con el resto de la sociedad. La pretendida preservación de la dignidad y el "carácter de majestad" del congreso se manifestaron, entre otras cosas, en una renuncia casi total a las presentaciones públicas fuera del edificio del congreso. Sin embargo, se le dio gran importancia a la comunicación con el pueblo, dado que aquí también los diputados perseguían objetivos educativos. Por lo tanto, la comunicación escrita, por ejemplo, la publicación de las leyes y de las actas de sesiones, tuvo un papel importante en sus relaciones con el resto de la sociedad. Al mismo tiempo, esa mediatización de la comunicación también buscaba crear una distancia entre el congreso y el pueblo, escenificando un orden político incuestionable.

Con esta apuesta por la historia regional, Sebastian Dorsch hace una importante aportación a una perspectiva historiográfica comparada, o bien múltiple, de los desarrollos supuestamente "generales" del México de comienzos del siglo xix. Además, su libro demuestra justamente la aplicación del concepto de cultura constitucional en un ente político concreto, confirmando así su valor heurístico. También es loable la abundancia de materiales que Dorsch procesó para contextualizar al estado de Michoacán con el mundo atlántico. Así, además de la

${ }^{4}$ Ernst H. Kantorowicz, The King's Two Bodies. A Study in Mediaeval Political Theology, Princeton, Princeton University Press, 1957. 
comparación con las distintas constituciones estatales de México, en diferentes ocasiones, el autor se refiere también a textos constitucionales de Alemania, Francia, España y los Estados Unidos. Asimismo puede criticarse que en algunos puntos la presentación de los resultados se hace demasiado detallada, sobre todo en la segunda parte del libro. Con un volumen de casi 600 páginas, quizá pocos lectores concluyan el libro en su totalidad. Si bien, para evitar este defecto, el autor presenta con amplitud sus conclusiones parciales, esto genera que en ocasiones se llegue a repeticiones casi textuales de algunos pasajes. Con todo, Sebastian Dorsch ha escrito un libro de valor plausible en el aún poco trabajado ámbito de la cultura constitucional. En un próximo paso, y como complemento a la perspectiva de elite adoptada en su trabajo, sería fascinante analizar los efectos de las normas constitucionales en los estratos sociales distintos de las elites políticas. Con todo, nos parece muy recomendable que este libro se traduzca al español.

\section{Alfredo Pureco Ornelas, Empresarios lombardos en Michoacán. La familia Cusi entre el Porfiriato y la Posrevolución (1884-1938), Zamora, El Colegio de Michoacán, Instituto Mora, 2010, 432 p.}

\section{Gladys Lizama Silva}

E

1 libro puede resumirse como el relato pormenorizado de las prácticas económicas efectuadas primero por un individuo y luego por el núcleo familiar de origen italiano: los Cusi, en la región de la Tierra Caliente michoacana durante 54 años comprendidos entre 1884 y 1938. Época por demás crucial en la historia de México y de Michoacán, porque recorre y presenta el auge porfiriano en uno de sus aspectos más relevantes: la agricultura y agroindustria capitalista de cultivos tropicales como el arroz; el espíritu emprendedor inagotable de los Cusi; el conflicto revolucionario de 1910 que en las haciendas comandadas por este grupo familiar no significó, ni mucho menos, la destrucción total de las fuentes productivas y, por último, la conformación de una sociedad posrevolucionaria proclive al cambio que hizo 